\title{
Dynamic film thickness between bubbles and wall in a narrow channel
}

\section{Journal Article}

\section{Author(s):}

Ito, Daisuke; Damsohn, Manuel; Prasser, Horst-Michael; Aritomi, Masanori

Publication date:

2011-09

Permanent link:

https://doi.org/10.3929/ethz-b-000039357

\section{Rights / license:}

In Copyright - Non-Commercial Use Permitted

\section{Originally published in:}

Experiments in Fluids 51(3), https://doi.org/10.1007/s00348-011-1105-3 


\title{
Dynamic film thickness between bubbles and wall in a narrow channel
}

\author{
Daisuke Ito • Manuel Damsohn • \\ Horst-Michael Prasser • Masanori Aritomi
}

Received: 24 November 2010/Revised: 14 April 2011/Accepted: 16 April 2011/Published online: 3 May 2011

(C) Springer-Verlag 2011

\begin{abstract}
The present paper describes a novel technique to characterize the behavior of the liquid film between gas bubbles and the wall in a narrow channel. The method is based on the electrical conductance. Two liquid film sensors are installed on both opposite walls in a narrow rectangular channel. The liquid film thickness underneath the gas bubbles is recorded by the first sensor, while the void fraction information is obtained by measuring the conductance between the pair of opposite sensors. Both measurements are taken on a large two-dimensional domain and with a high speed. This makes it possible to obtain the two-dimensional distribution of the dynamic liquid film between the bubbles and the wall. In this study, this method was applied to an air-water flow ranging from bubbly to churn regimes in the narrow channel with a gap width of $1.5 \mathrm{~mm}$.
\end{abstract}

\section{Introduction}

In a boiling water reactor, the coolant flowing into the rod bundle is heated up to the evaporation temperature. A twophase flow is formed and a transition of the flow regime from bubbly flow to slug, churn, and finally annular mist flow takes place. Initially, the individual bubble behavior

D. Ito $(\square) \cdot$ M. Damsohn $\cdot$ H.-M. Prasser

Department of Mechanical and Process Engineering,

ETH Zürich, ML K 14 Sonneggstrasse 3, 8092 Zurich, Switzerland

e-mail: ito@lke.mavt.ethz.ch

D. Ito $\cdot$ M. Aritomi

Research Laboratory for Nuclear Reactors,

Tokyo Institute of Technology, 2-12-1-N1-13 Ohokayama,

Meguro-ku, Tokyo 152-8550, Japan dominates the flow in the regimes of bubbly and slug flows, which are characterized with low void fraction. However, it is very important to pay attention to the thin liquid film remaining between bubble and wall, especially in narrow channels. In the development of high-performance and high-conversion boiling water reactors, the reduction in the size of the cooling channel is a key to a harder neutron spectrum yielding higher conversion rates of fertile material, like U-238 into the fissile nuclides. By this measure, the fuel efficiency can be strongly increased. Reduced moderation water reactors that adapt the approach of tightlattice rod bundle to increase the conversion ratio are discussed by Iwamura et al. (2006) and Ohnuki et al. (2008). It is clear that this poses new challenges to the cooling of the fuel rods in normal operation as well as under accident conditions. In particular, it is expected that in heated channels, local dryout may pose limits to the decrease in the size of the cooling channel. In other words, it is of fundamental interest to develop an experimental methodology to determine the liquid film thickness between gas bubbles or plugs and the wall in a tight-lattice rod bundle. The experiments presented in this paper are dedicated to the test of a novel measuring technique, which is applied to an adiabatic gas-liquid flow in a narrow rectangular gap. It is characterized by a high spatial and time resolution. Later, it is planned to implement the new method in a test bundle with a real prototypal geometry.

In the previous investigations into two-phase flow measurement in rod bundle, the differential pressure technique and local void probes have been mainly applied to evaluate the averaged flow field (Sadatomi et al. 2004; Tamai et al. 2006; Yun et al. 2008). Furthermore, it is difficult even for wire-mesh tomography (Prasser et al. 1998) and neutron radiography (Kureta 2007), which receives attention recently, to measure spatial distributions 
of bubble and liquid film behaviors in bundle channel with high time resolution. Hence, there is a strong motivation to search for alternative two-phase measuring techniques in rod bundles, especially for the case of a tight-lattice in reduced moderation cores.

For that purpose, the authors focused on a liquid film sensor developed by Damsohn and Prasser (2009a). This sensor can provide two-dimensional liquid film thickness distributions from the electrical conductance between electrodes mounted directly on the surface of the channel walls. The particular advantage of this method is its high spatio-temporal resolution. Film sensors have already be applied to a double subchannel geometry resembling a square-lattice rod bundle. In a corresponding circulation loop with a vertical test channel, the liquid film behavior in the annular flow regime has been evaluated (Damsohn and Prasser 2010). In previous studies, flat versions of the liquid film sensor were used in a horizontal channel of square cross-section (Damsohn and Prasser 2009a, b). Based on the positive experience, the decision was taken to apply the sensor to instrument the walls of a narrow channel in order to study different two-phase flow regimes in narrow gaps as a preliminary study to measure the liquid film behavior in narrow fuel rod bundle geometry.

On the other hand, a novel measurement method has been developed by the authors to detect the bubble size and shape as well as to measure the void fraction distribution in a narrow channel (Ito et al. 2010). This is also based on electrical conductance, whereas the wire electrodes are arranged on the opposing walls of the rectangular channel. In this arrangement, the local presence of the gaseous phase causes a sharp decrease in the electrical current measured at the given crossing point of transmitter and receiver electrodes and instantaneous two-dimensional distributions of the gas fraction in the narrow gap can be obtained. The bubbles are identified as connected regions of low conductance; hence, individual parameters of each bubble can be estimated, like size, interfacial area, and velocity. This individual bubble estimation can be applied to the present measurement method in the future. This void fraction measurement is therefore an effective way to understand the flow structure in the narrow channel.

\section{Simultaneous void fraction and liquid film measurements}

\subsection{Principles}

In the present study, the gas detection by electrodes on the opposing walls is combined with a simultaneous measurement of the liquid film thickness. For this purpose, a pair of liquid film sensors is installed on both walls of narrow channel. A schematic diagram of the measurements is given in Fig. 1. As long as the conducting liquid phase bridges the narrow gap between the opposing walls, the electrical excitation of a transmitter electrode of one of the film sensors results in the registration of a current at the close-by receiver electrodes of both opposing sensors, while in case of the presence of a bubble, the current to the opposing sensor is interrupted. In the latter case, there is still a current measured at the excited sensor itself, which originates from the conductance of the remaining liquid film covering transmitter and receiver electrodes on this sensor. Hence, the film sensor, at which the transmitter electrodes are activated, can be used to measure the liquid film thickness between the wall and the passing-by bubbles, while the void fraction in the narrow gap is calculated from the conductivity distribution received by the opposing sensor. Repeating the measuring cycle for all transmitter lines, two-dimensional distributions of liquid film thickness and void fraction can be obtained.

In this study, a pair of film sensors developed by Damsohn and Prasser (2009b) is applied. The electrical conductance measurements are carried out by a wire-mesh electronics unit with 128 transmitter outputs and 128 receiver inputs, from which 16 transmitters and 128 receivers are used. In particular, 16 outputs of the electronics are connected to the transmitter electrodes of the first film sensor, the 64 receiver electrodes of which occupy the first half of the available inputs of the electronics. In the same time, the receiver electrodes of the second sensor opposing the first one are connected to the second set of 64 inputs. The transmitter electrodes of the second sensor are not used and put on ground potential. In this configuration, benefit can be taken from the maximum measuring frequency of the system of $10 \mathrm{kHz}$ for both sensors together.

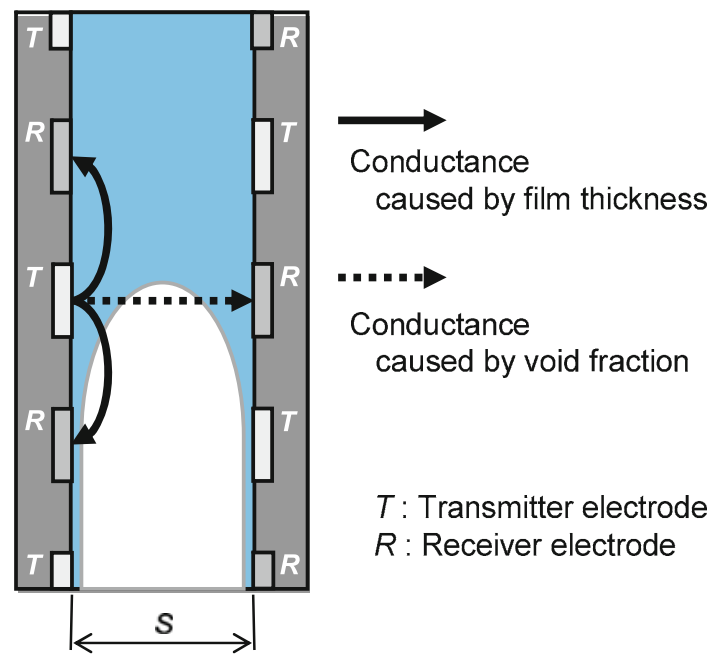

Fig. 1 Schematic diagram of narrow two-phase flow measurement based on electrical conductance 


\subsection{Liquid film sensor}

The liquid film thickness on the sensing surface is measured from the conductance between transmitter and receiver electrode lying next to each other. Fig. 2 shows the simplified scheme of electrical circuit for liquid film thickness measurement. The electrical conductance is measured by switching the circuit of transmitting side at high speed. The electrode arrangement of the film sensor is illustrated in Fig. 3. The sensor consists of transmitter, receiver, and ground electrodes. The distance between measuring electrodes and ground spots is $1 \mathrm{~mm}$. Both transmitter and receiver electrodes have a diameter of $0.5 \mathrm{~mm}$, and the ground spots have a diameter of $0.9 \mathrm{~mm}$. The total elementary cell of electrodes has the lateral dimensions of $2 \mathrm{~mm}$, which is equivalent to the spatial resolution of the measuring matrix, i.e., each measuring point corresponds to a surface area of $2 \times 2 \mathrm{~mm}^{2}$.

In order to estimate the liquid film thickness from measured electrical conductance, a calibration is needed. The dependency of the conductance as function of film

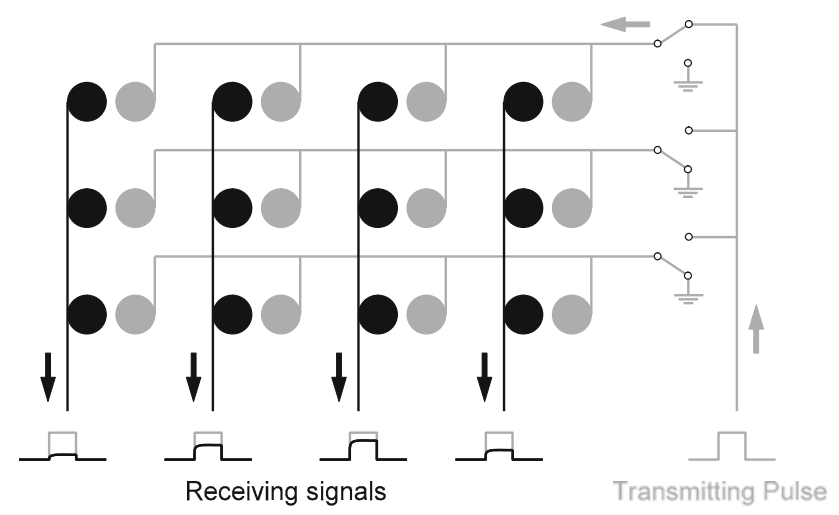

Fig. 2 Simplified electrical scheme of liquid film sensor

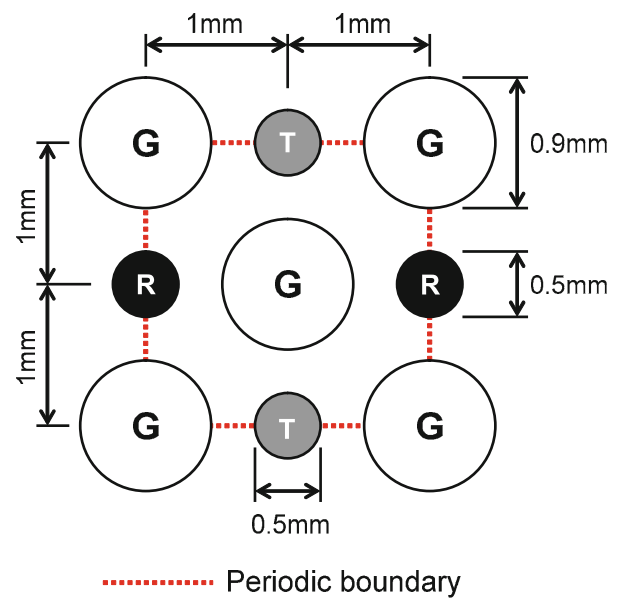

Fig. 3 Geometry of the sensor electrodes ( $T$ transmitter, $R$ receiver, $G$ ground) thickness is nonlinear. Furthermore, the instrument constant can vary between individual measuring points due to manufacturing tolerances. In this study, nonconductive cylindrical rollers with the grooves ranging from 100 to $1,000 \mu \mathrm{m}$ are applied. They are rolled over the sensor, as shown in Fig. 4. The final signal from the electronic unit is recoded when the roller passes above the electrodes. In this way, the sensor is calibrated together with the signal acquisition electronics. Dimensionless currents are calculated from the ratio of the value measured for a certain known film thickness and the saturation value. The latter is obtained from a measurement with a thickness of the water layer bigger than the sensibility range of the sensor, i.e., a thickness, at which the measured signal converges to the asymptotic one for an infinite water layer. The calibration results are plotted in Fig. 5. The horizontal axis is the dimensionless current and the vertical one is film thickness. It is found that the conductance is almost saturated above a thickness of $600 \mu \mathrm{m}$. Hence, the applied film sensor can measure the thickness less than about $500 \mu \mathrm{m}$.

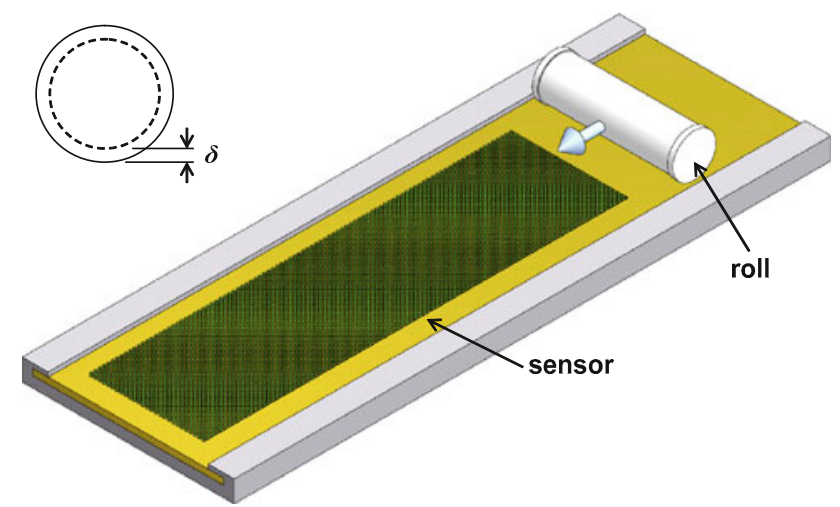

Fig. 4 Calibration set-up to measure the reference film thickness

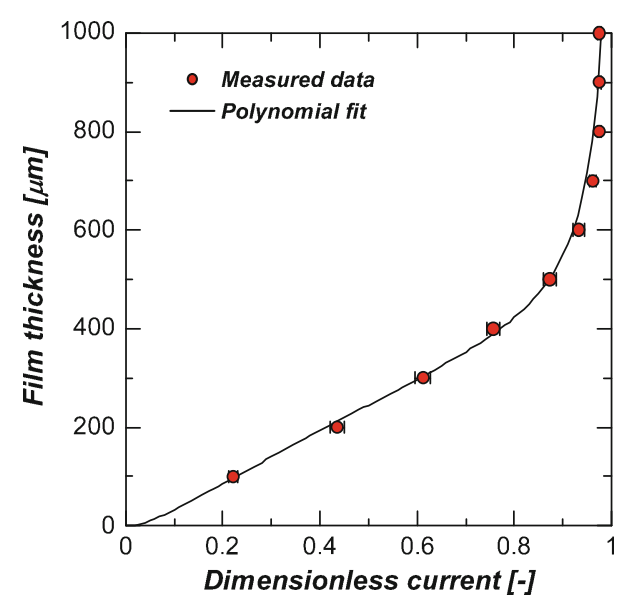

Fig. 5 Calibration curve for the film thickness 
A polynomial calibration function (Eq. 1) based on a fourth-order polynomial function is adapted to obtain the film thickness from measured conductance. The denominator of the function is a second-order polynomial serving to reflect the asymptotic behavior of the measuring signal. The coefficients of the function are fitted to match the calibration values.

$\delta_{i, j, k}=\frac{a_{1} x^{4}+a_{2} x^{3}+a_{3} x^{2}+a_{4} x+a_{5}}{\left(x-b_{1}\right)\left(x-b_{2}\right)}$

$x=\frac{\sigma_{i, j, k}}{\sigma_{L}}$

where $\sigma_{i, j, k}$ is a measured conductance and $\sigma_{L}$ is that at saturation condition. $i, j$ and $k$ are the indices representing the sampling data number, the transmitter, and receiver electrodes, respectively. In the polynomial equation, $b_{1}$ and $b_{2}$ are the poles of the calibration function. The coefficients $a_{1}$ to $a_{5}$ are estimated individually for each measurement point in the two-dimensional sensor matrix. The result of the polynomial fit is also shown in Fig. 5.

\subsection{Void fraction estimation}

The local void fraction between transmitter and receiver electrodes facing each other can be calculated from the measured conductance. In the sensor used in this study, there are a lot of ground electrodes, so electrical field between two sensors has high directive property. This means that the local conductance signal originates from a small focus area around the center of mass of the active electrodes. In this study, the void fraction is assumed to be proportional to the electrical conductance. Thus, the following equation is used to estimate the instantaneous local void fraction from measured conductance.

$\varepsilon_{i, j, k}=\frac{\sigma_{L}-\sigma_{i, j, k}}{\sigma_{L}-\sigma_{G}}=1-\frac{\sigma_{i, j, k}}{\sigma_{L}}$

where $\sigma_{L}$ and $\sigma_{G}$ are the conductance of plain liquid and plain gas, respectively.

\section{Experimental set-up}

The scheme of the test channel is given in Fig. 6. The narrow channel with a gap width $s$ is constructed by flanging distance plates with the desired thickness $s$ between the opposing channel walls. The length of the test channel is $1,450 \mathrm{~mm}$ and the width $w$ is constant over height. In this study, $s=1.5 \mathrm{~mm}$ and $w=32 \mathrm{~mm}$. The flow is a vertical upward air-water flow. Water is supplied from the lower part of the channel, and the flow rate is monitored by a rotameter. Air is injected from an orifice with $0.5 \mathrm{~mm}$ diameter in the front wall at a height of
$170 \mathrm{~mm}$ from the water inlet and a center point of channel width. The air flow rate is controlled by a mass flow controller (MFC). The air-water mixture passes through the test section and exits from the upper part of the channel. The measurement section is located at a height of $900 \mathrm{~mm}$ from the air inlet.

As mentioned above, a pair of film sensors is installed on both front and back walls of the channel. Both sensors together form a measuring matrix of 16 transmitters and 128 receivers with a total number of 2,048 measurement points. At this size of the sensor matrix, the applied wiremesh sensor electronics unit allows to run the measurement at a speed of $10 \mathrm{kHz}$. In the result, $16 \times 64(=1,024)$ points are available for the measurement of the liquid film

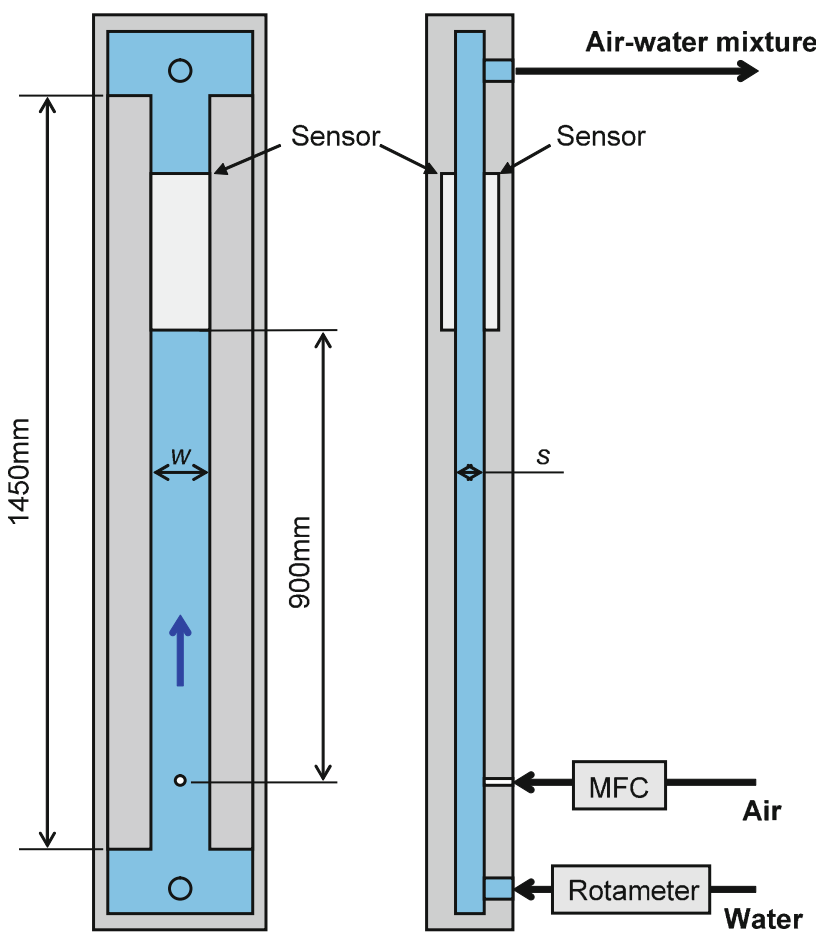

Fig. 6 Schematics of experimental narrow channel

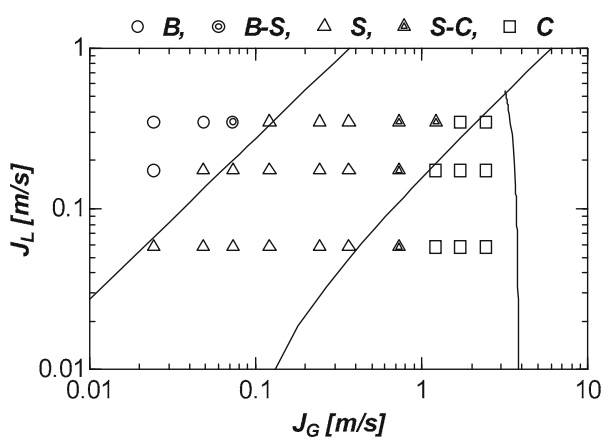

Fig. 7 Experimental conditions on the flow regime map of Hibiki and Mishima (2001) in a narrow channel with cross-section of $32 \times 1.5 \mathrm{~mm}^{2}$, ( $B$ bubbly flow, $S$ slug flow, $C$ churn flow $)$ 
thickness, and other $16 \times 64(=1,024)$ points are used for the void fraction measurement. The spatial resolution of both sensors is $2 \times 2 \mathrm{~mm}^{2}$. Therefore, the instrumented area has the dimensions of $32 \times 128 \mathrm{~mm}^{2}$.
The measurements are taken at various different superficial gas and liquid velocities. The flow conditions are plotted in flow regime map developed by Hibiki and Mishima (2001), as shown in Fig. 7. The flow regimes are
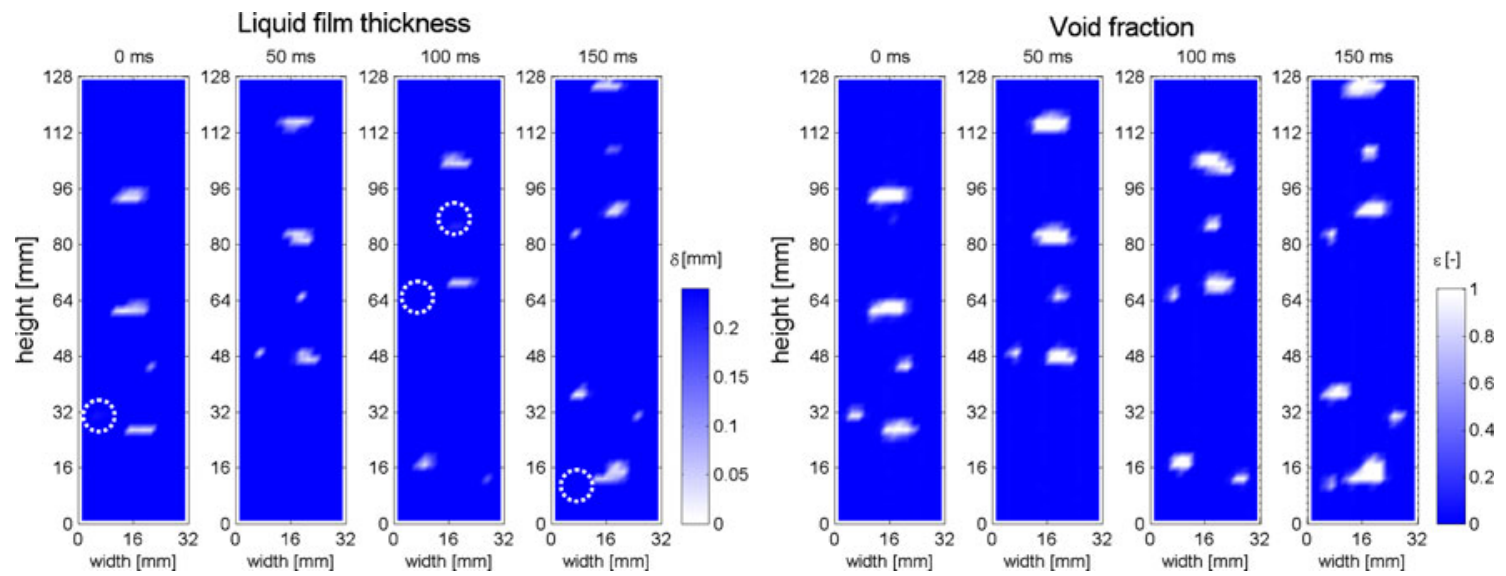

Fig. 8 Typical instantaneous distributions of film thickness and void fraction in bubbly flow at $J_{G}=0.024 \mathrm{~m} / \mathrm{s}$ and $J_{L}=0.347 \mathrm{~m} / \mathrm{s}$
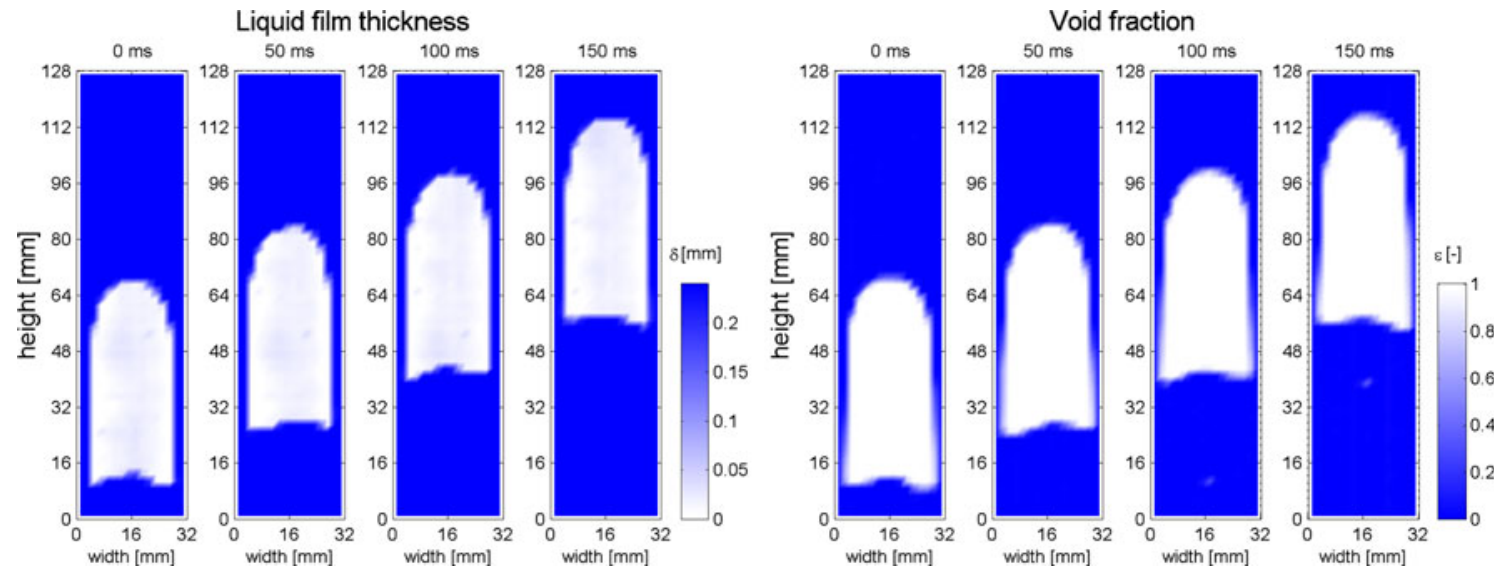

Fig. 9 Typical instantaneous distributions of film thickness and void fraction in slug flow at $J_{G}=0.073 \mathrm{~m} / \mathrm{s}$ and $J_{L}=0.174 \mathrm{~m} / \mathrm{s}$
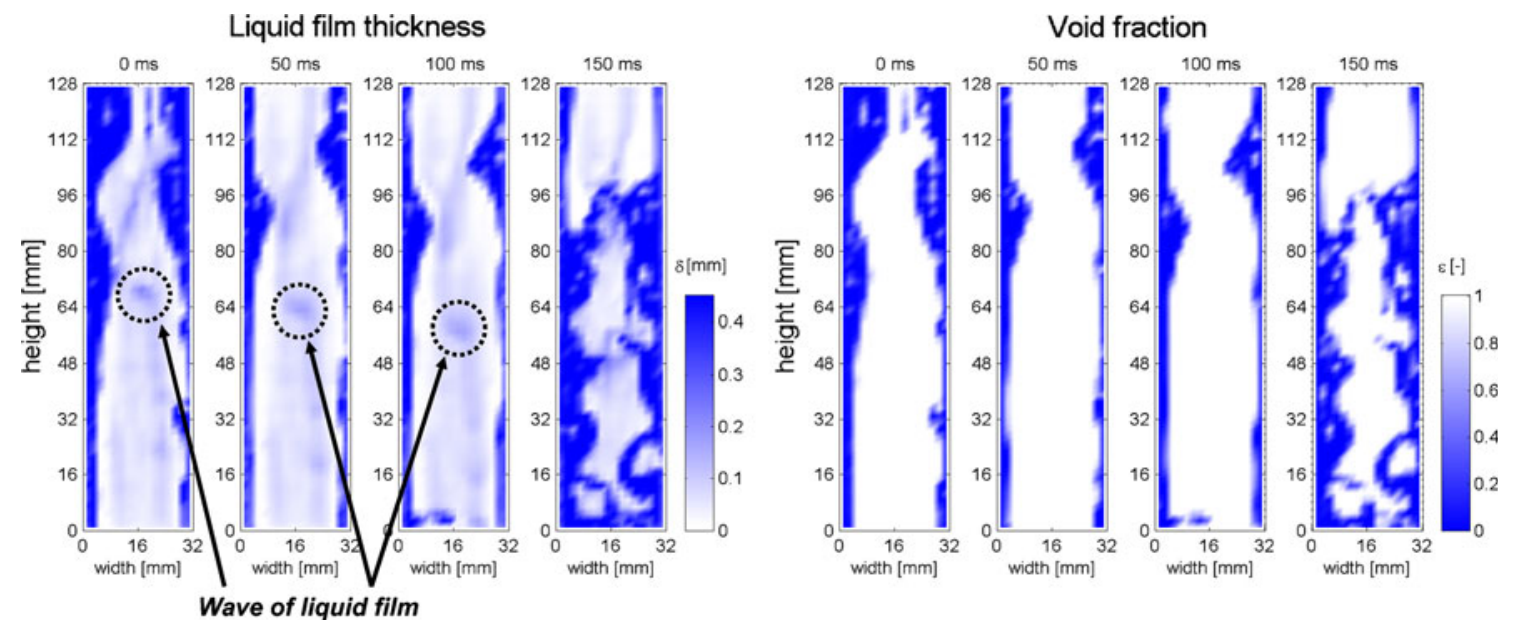

Fig. 10 Typical instantaneous distributions of film thickness and void fraction in churn flow at $J_{G}=1.7 \mathrm{~m} / \mathrm{s}$ and $J_{L}=0.347 \mathrm{~m} / \mathrm{s}$ 
Fig. 11 Reconstruction of

bubble width distribution;

a bubbly flow in Fig. 8, b slug

flow in Fig. 9, c churn flow in

Fig. 10
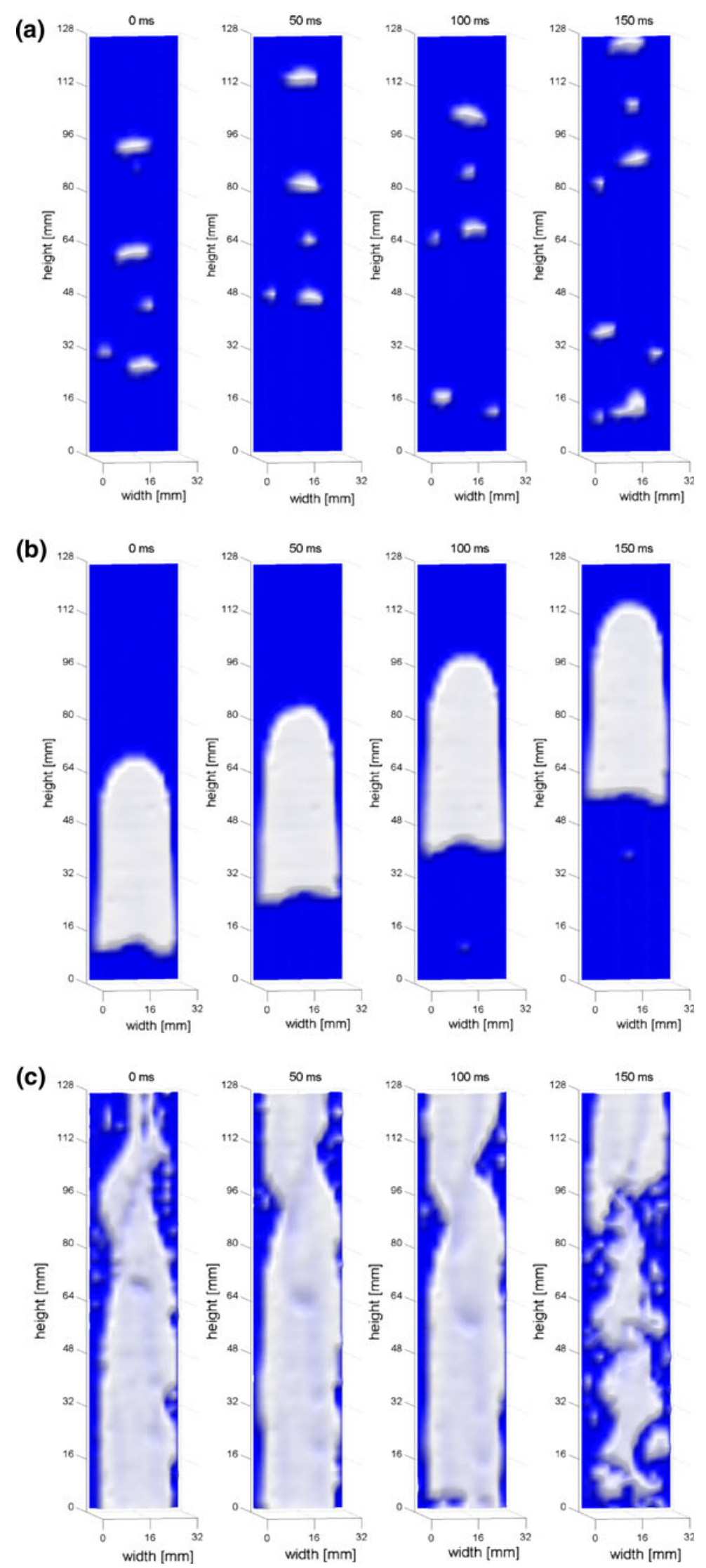
identified by visual observation before and after the test run. According to this map, bubbly, slug, and churn flows can be created in the channel.

\section{Results}

\subsection{Instantaneous distributions}

Typical results for bubbly flow, slug flow, and churn flow are shown in Figs. 8, 9 and 10, respectively. In the plots of selected instantaneous two-dimensional distributions, both film thickness and void fraction are displayed using a color scale. Characteristic images of individual bubbles are found in case of bubbly flow, as shown in Fig. 8. Although all bubbles are visible in the void fraction plots, some bubbles cannot be seen in liquid film thickness distribution. Locations, where bubbles are missing, that are found in the void fraction distribution are marked by dashed circles in Fig. 8, left side. In these cases, the bubble surface is too far from the sensor plane, and the distance between bubble and sensor is out of the measurement range of the film thickness. In slug flow with large Taylor bubbles, the shape of bubbles is represented well not only in the void fraction distribution but also in the liquid film thickness. In addition, it is found that very thin films are formed between the Taylor bubble and the wall. The liquid film behavior and gaseous phase structure become significantly transient in the churn flow region. It is seen that waves of liquid travel down. In Fig. 10, an example of such a wave is marked by a dashed circle.
Fig. 12 Time-series profiles at a measurement point; a bubbly flow, b slug flow, c churn flow
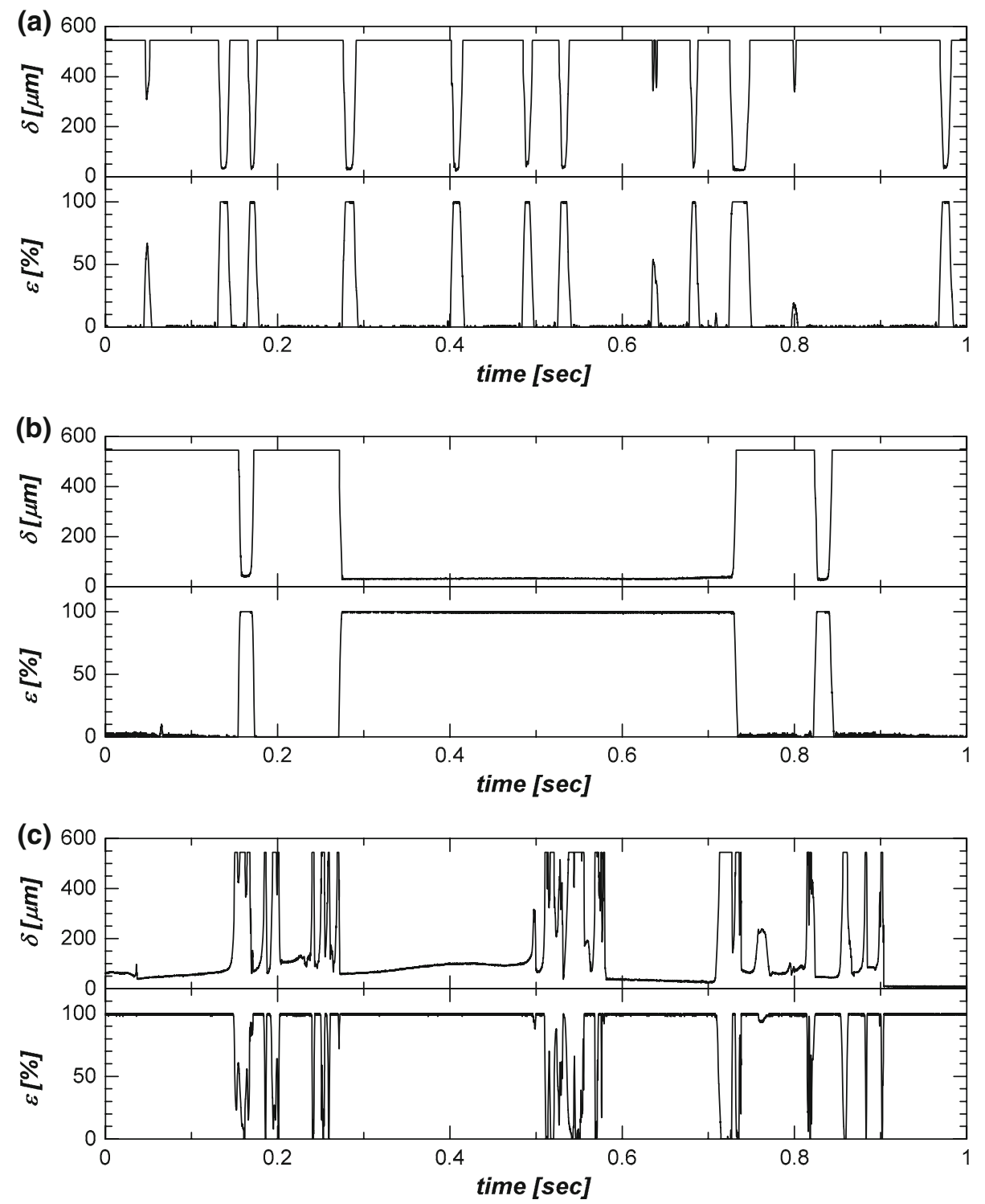
4.2 Reconstruction of the bubble width in the narrow gap

Due to the presence of the liquid film between bubbles and channel walls, the gaseous phase does not fill the narrow gap between front and back walls completely. In this section, the data obtained by the liquid film measurement and the void fraction data are fused to produce unified information on the instantaneous two-dimensional distribution of the size of the gas-filled part of the channel width. This parameter is called bubble width. If the bubbles are small, then the liquid film measurement is unreliable and the bubble size in the direction of the gap width is rather characterized by the void fraction measurement. When a large bubble completely blocks the current between both opposing sensors, then the measured void fraction turns to $100 \%$, which is in this case unrealistic, because there might still be liquid films. The latter are characterized by the liquid film measurement. In other words, it is desirable to calculate the bubble width from the one of both measured quantities that characterizes it in the best possible way depending on the given situation. A threshold for the void fraction of $50 \%$ was introduced to distinguish between the cases where the void fraction or the liquid film thickness has to be used as measure for the bubble width $\delta_{\text {bub }}$, which finally is calculated using the following equation:

$$
\begin{array}{ll}
\frac{\delta_{\text {bub }}}{2}=\frac{s}{2}-\delta & \text { for } \quad \varepsilon \geq 0.5 \\
\frac{\delta_{\text {bub }}}{2}=\frac{s}{2} \times \varepsilon & \text { for } \quad \varepsilon<0.5
\end{array}
$$

Figure 11 shows instantaneous two-dimensional distributions of the bubble width estimated by above approach. The results in Fig. 11a-c correspond to Figs. 8, 9 , and 10 , respectively. In bubbly flow, individual bubble motions can be seen in the images in Fig. 11a. The slug bubbles are also well visualized in Fig. 11b. Finally, churn flows show a very complicated structure with numerous (a)
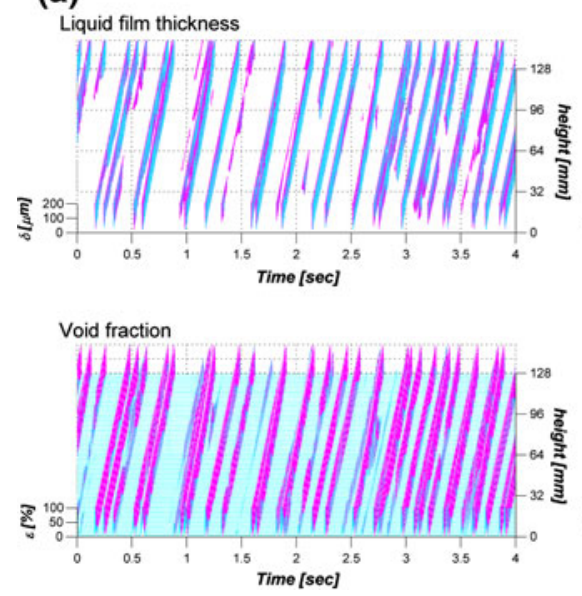

(b)

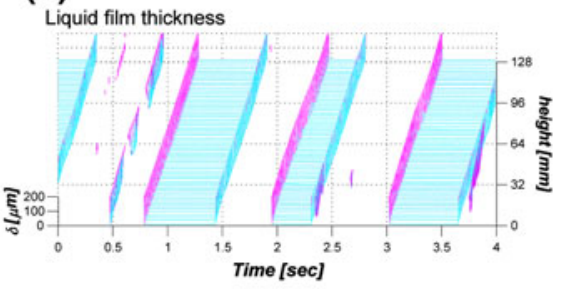

(c)

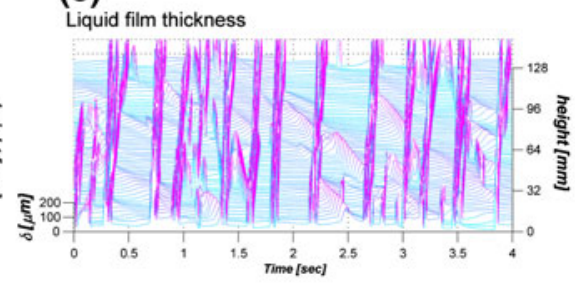

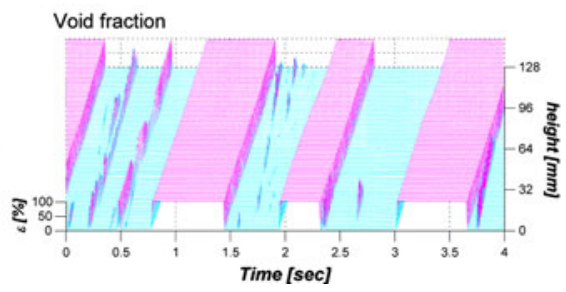

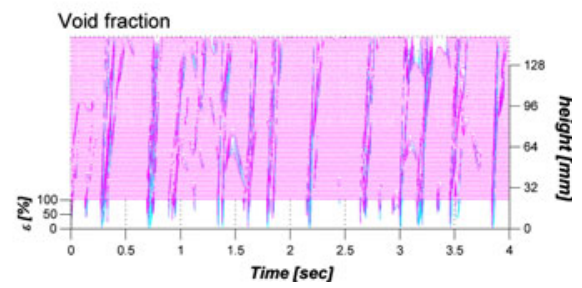

Fig. 13 Spatio-temporal distribution at the channel center; a bubbly flow with $J_{G}=0.024 \mathrm{~m} / \mathrm{s}, J_{L}=0.347 \mathrm{~m} / \mathrm{s}, \mathbf{b}$ slug flow with $J_{G}=0.122$ $\mathrm{m} / \mathrm{s}, J_{L}=0.058 \mathrm{~m} / \mathrm{s}$, c churn flow with $J_{G}=1.7 \mathrm{~m} / \mathrm{s}, J_{L}=0.058 \mathrm{~m} / \mathrm{s}$
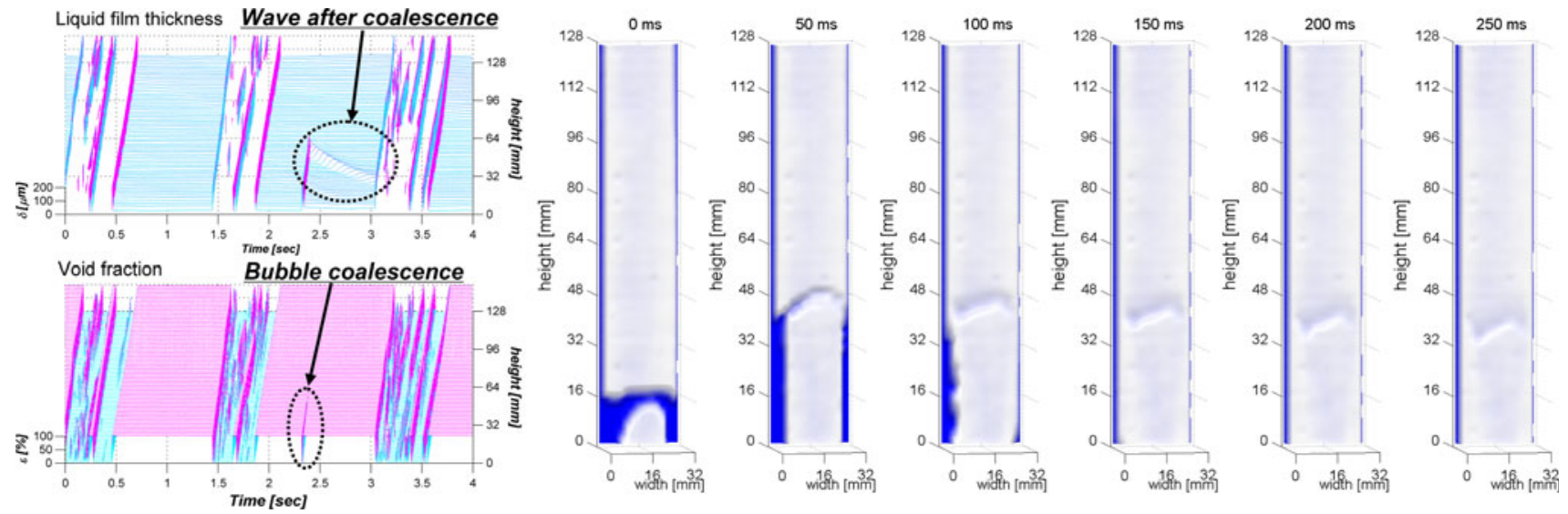

Fig. 14 Spatio-temporal distribution and reconstructed bubble width images of bubble coalescence $\left(J_{G}=0.365 \mathrm{~m} / \mathrm{s}, J_{L}=0.058 \mathrm{~m} / \mathrm{s}\right)$ 


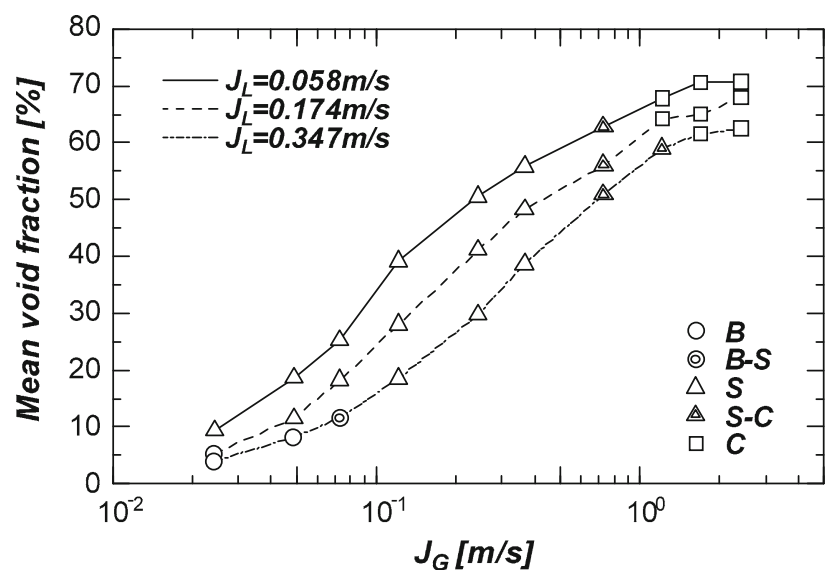

Fig. 15 Mean void fractions and flow regimes

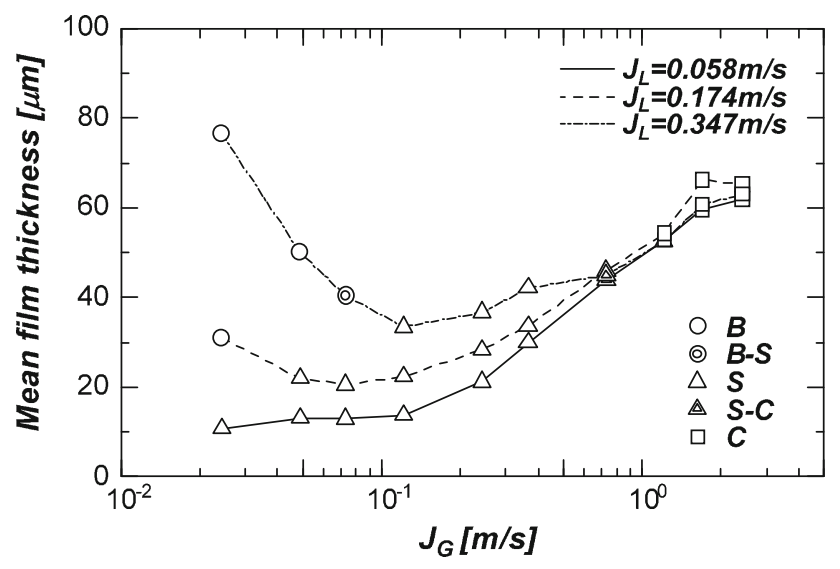

Fig. 16 Mean liquid film thicknesses and flow regimes events of coalescence and breakup of bubbles, as shown in Fig. 11c.

\subsection{Time-series profiles}

The time-series distributions of liquid film thickness and void fraction are used to understand the flow structure. The time-series profiles at a measurement point located in the middle of the sensing area are shown in Fig. 12. Both film thickness and void fraction are plotted. In the figures, the width of the peaks corresponds to the bubble size, because the bubbles pass through the fixed measurement point with a nearly constant velocity. Therefore, the bubbly flow regime has many small bubbles, as shown in Fig. 12a. The peaks in the film thickness and void fraction in bubbly flow show the similar shape, while of course pointing toward an increase in case of the void fraction and toward a decrease in case of the film thickness. In Fig. 12b, the film thickness at the middle point of channel width is nearly constant underneath the Taylor bubble. On the other hand, the film thickness varies significantly in the case of churn flow.

Figure 13 shows the spatio-temporal distributions on the middle line of channel width. The horizontal axis is the time. The plots show the instantaneous value of the measured quantity as a manifold of curves plotted against a vertical axis representing film thickness or, respectively, void fraction. The corresponding axis is shown on the left side of the graphs. Each individual curve is plotted with an axial offset representing the vertical coordinate within the
Fig. 17 Typical individual bubble film behavior for bubbles with different size at $J_{L}=0.174 \mathrm{~m} / \mathrm{s} ;$ a film thickness and void fraction profiles along the channel width, b reconstructed bubble width distribution (a)

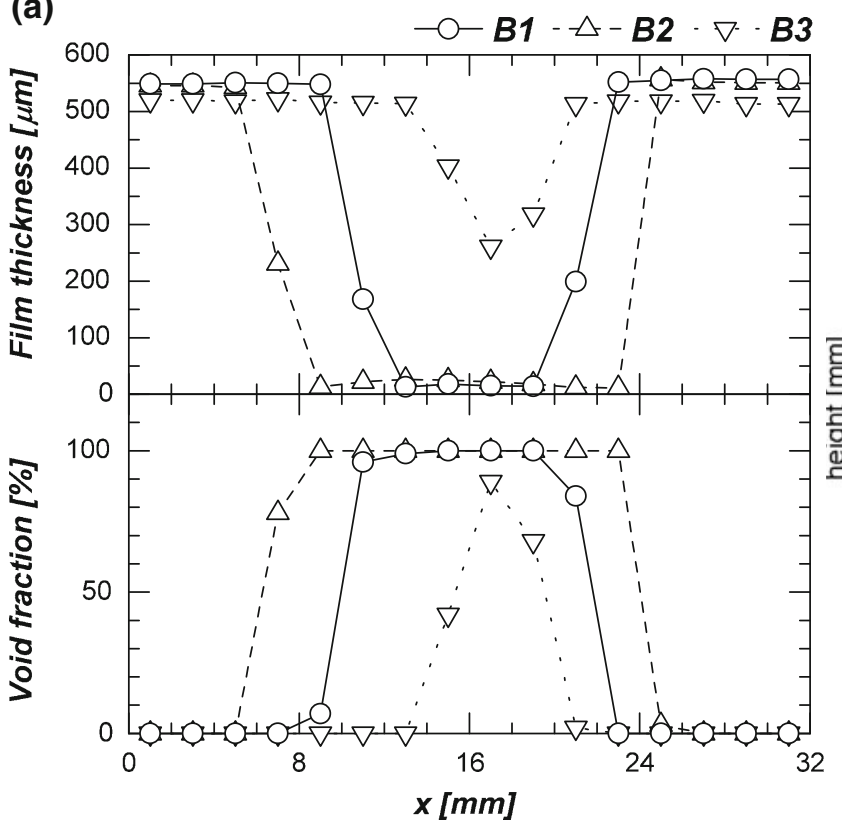

(b)

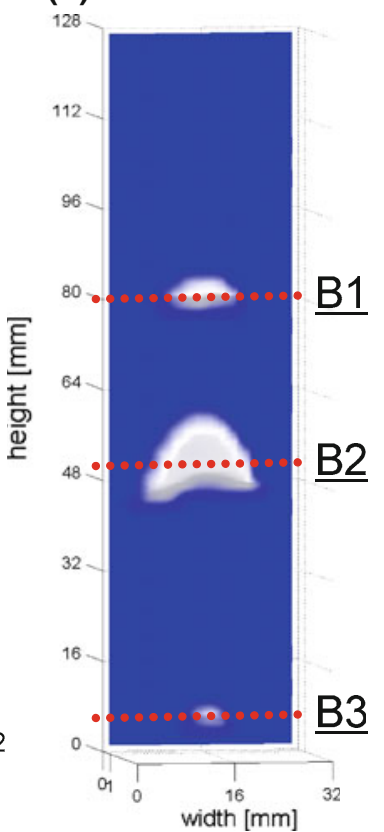


sensor matrix, as shown on the secondary axis on the right side of each figure.

In these distributions, it is obvious that the bubbles flow upward with time. In the bubbly flow regime in Fig. 13a, the number of bubbles reaching a liquid film thickness below $200 \mu \mathrm{m}$, which was chosen as upper limit of the graph, is smaller than the number of bubbles found in the void fraction signal. In slug flows, the liquid film is very thin in Fig. 13b. There is less variation in film thickness between slug bubbles and the wall. In case of churn flow
(Fig. 13c), characteristic wave structures occur in liquid film.

The inclination of the patterns in Fig. 13 is a measure for the velocity of the gaseous phase. The experiments shown in Fig. 13b, c were recorded at the same superficial liquid velocity. The fact that the gradient of the lines characterizing the propagation of the gas-liquid interface becomes larger with growing superficial gas velocity, which means that interface velocity increases with growing superficial gas velocity.

(a)

$-O-B 1-\triangle-B 2$
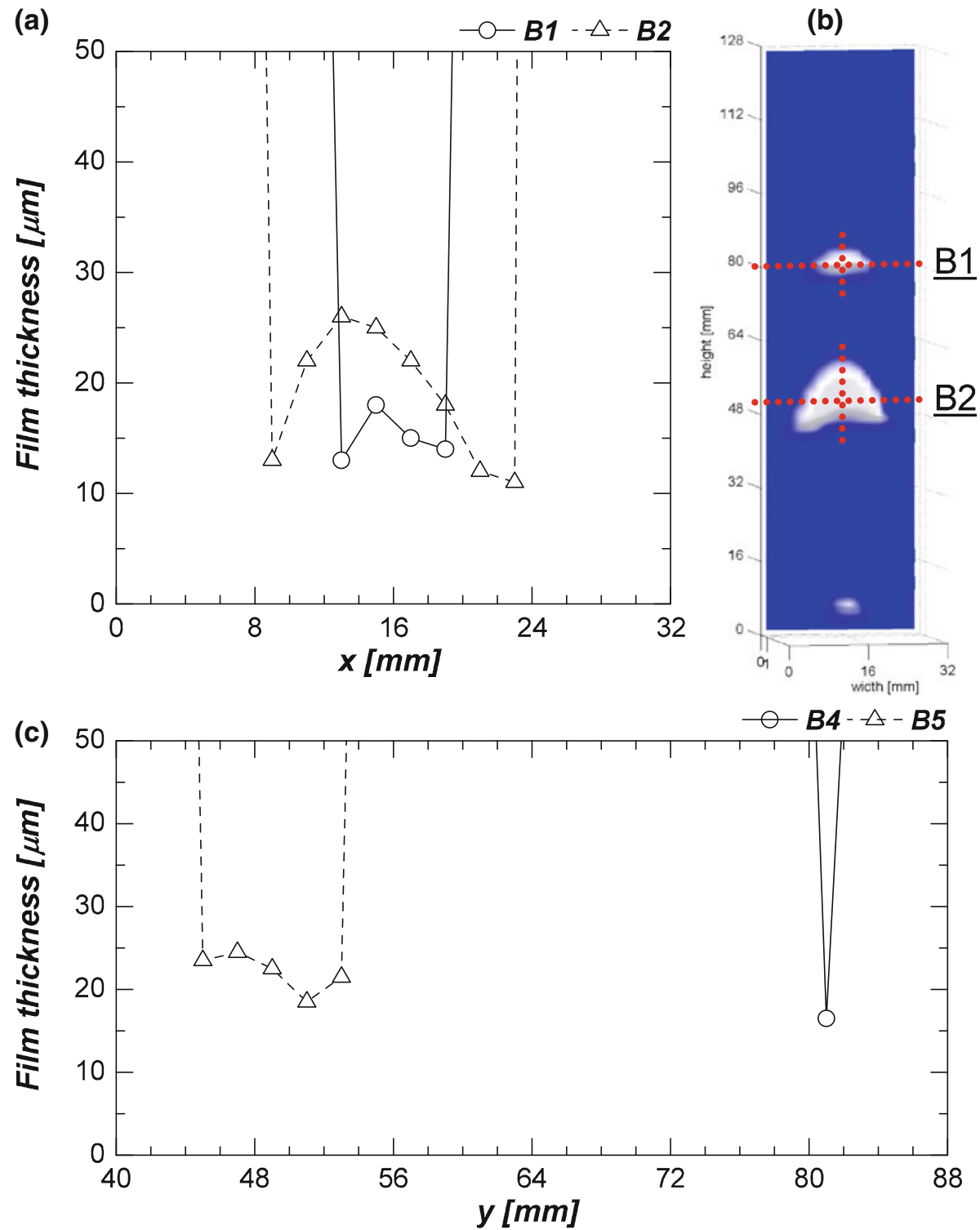

Fig. 18 Typical individual bubble film behavior for bubbles with different size at $J_{L}=0.174 \mathrm{~m} / \mathrm{s}$; a magnified profile of film thickness along the channel width, $\mathbf{b}$ reconstructed bubble width distribution, $\mathbf{c}$ film thickness profile along the center line 
The typical result of coalescence between two bubbles is shown in Fig. 14. There is a change of film thickness at about $2.3 \mathrm{~s}$ in the spatio-temporal distribution. Here, coalescence between a pair of slug bubbles occurs. After the coalescence, a wave of increased liquid film thickness is observed in the region occupied by the Taylor bubble that is formed as a result of the coalescence. In the reconstructed images, the liquid film behavior after coalescence of a pair of slug bubbles is also observed. Before the coalescence happens, the liquid bridge separating the bubbles is moving upward with nearly the gas phase velocity. After the breakage of the separating water film, the portion of liquid immerses into the liquid film, the thickness of which grows in turn. The region of increased film thickness, or, correspondingly, decreased bubble width, starts draining down under the action of gravity. From these results, we can conclude that the liquid in the films is moving with smaller velocities as the liquid separating individual bubbles.

\subsection{Averaged flow properties}

The mean void fraction is calculated by averaging the measured values at all measurement points of the sensors. The result of mean void fraction is shown in Fig. 15. In the plots, the flow regimes are indicated by using different symbols for the data points. From this figure, void fraction grows as $J_{G}$ increases and $J_{L}$ decreases. This tendency is similar to the behavior of the void fraction in the larger pipe. It is found that the transition from bubbly to slug flow takes place at a void fraction of about $10 \%$. Although void fraction increases proportionally with increasing $J_{G}$ in slug flow, the increasing rate becomes very low in churn flow.

A threshold of void fraction is used to evaluate the liquid film thickness on the bubble surface. The film thicknesses corresponding to void fraction above the threshold value are extracted and averaged only for those points. The mean liquid film thickness for each flow condition is shown in Fig. 16. In this result, the threshold is set (a)

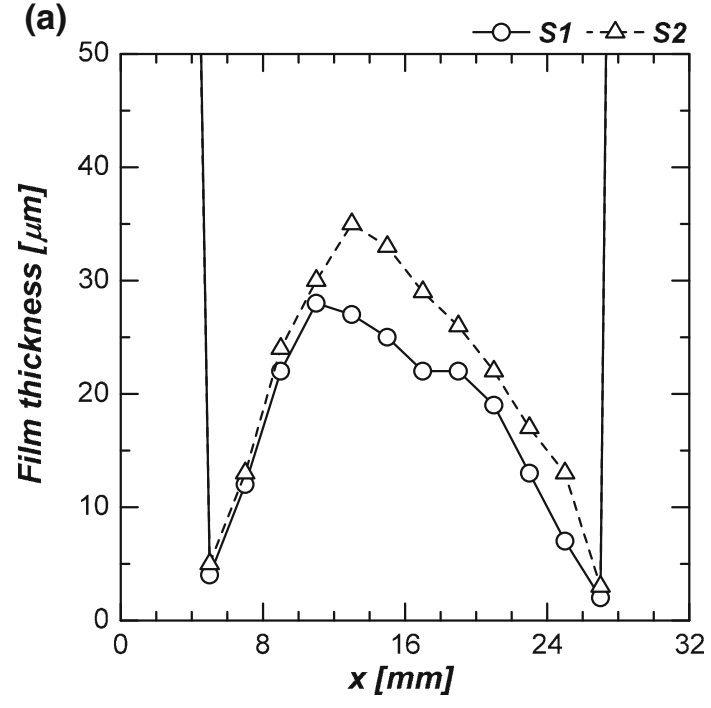

(b)

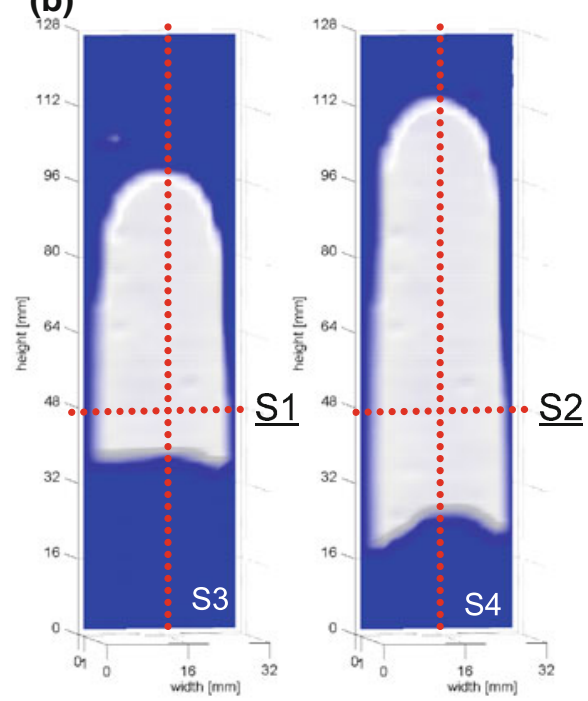

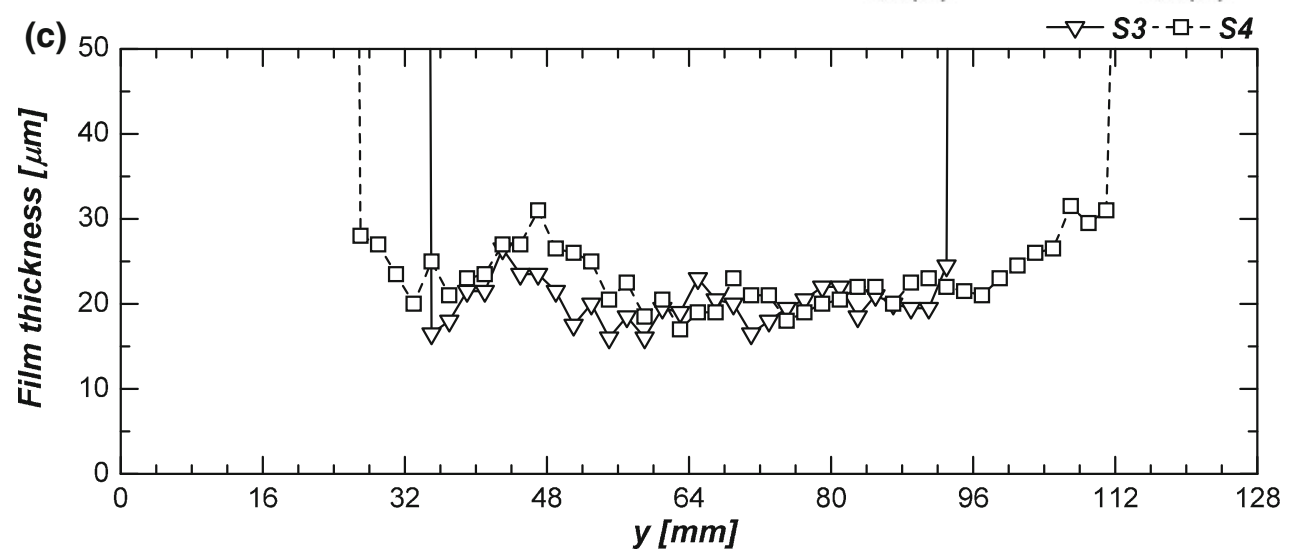

Fig. 19 Typical individual bubble film behavior for Taylor bubble with $J_{L}=0.174 \mathrm{~m} / \mathrm{s}$; a magnified profile of film thickness along the channel width, $\mathbf{b}$ reconstructed bubble width distribution, $\mathbf{c}$ film thickness profile along the center line 
$90 \%$. In the bubbly flow regime, most of bubbles are compressed in the gap direction. Still, the liquid film between bubble and channel wall is quite thick in this case. The film thickness becomes small in the slug flow regime. The film under the Taylor bubbles has a thickness, which is less dependent from the $J_{G}$ than in case of the bubbly flow. However, the film thickness increases when $J_{L}$ increases. In the churn flow regime, the liquid film thickness restarts growing with increasing $J_{G}$. The film thickness becomes nearly independent from the $J_{L}$.

\subsection{Individual bubble properties}

In this section, a zoom into instantaneous film thickness profiles for selected individual bubbles is performed. The profiles of void fraction and film thickness on horizontal lines cutting the bubble along its diameter are shown in Fig. 17a for different bubble diameters. The small bubble on line B3 in Fig. 17b has a void fraction less than $100 \%$ and displays a thick liquid film. It must be kept in mind that bubbles smaller or close to the lateral resolution of the film sensor create pronounced three-dimensional domains for the establishing of the electrical potential field between the pair of measuring electrodes. It is difficult to attribute the reading of the sensor in such a case to a well-defined film thickness, i.e., for small bubbles, the liquid film thickness measurement is not reliable. A conclusion on the minimum film thickness underneath of a bubble smaller than the resolution of the sensor cannot be made or is at least not straightforward. With increasing bubble diameter, the void fraction reaches $100 \%$. Then the film thickness between the bubble and the wall becomes reliable. Films of 10-25 $\mu \mathrm{m}$ thickness were detected for the selected bubbles. Magnified plots of the film thickness on the lines B1 and B2 are shown in Fig. 18a. It is observed that the film thickness is bigger in the center of the bubbles than at the periphery. This means that the liquid films have a dimple close to the bubble center of the channel width, and the bubble width is (a)

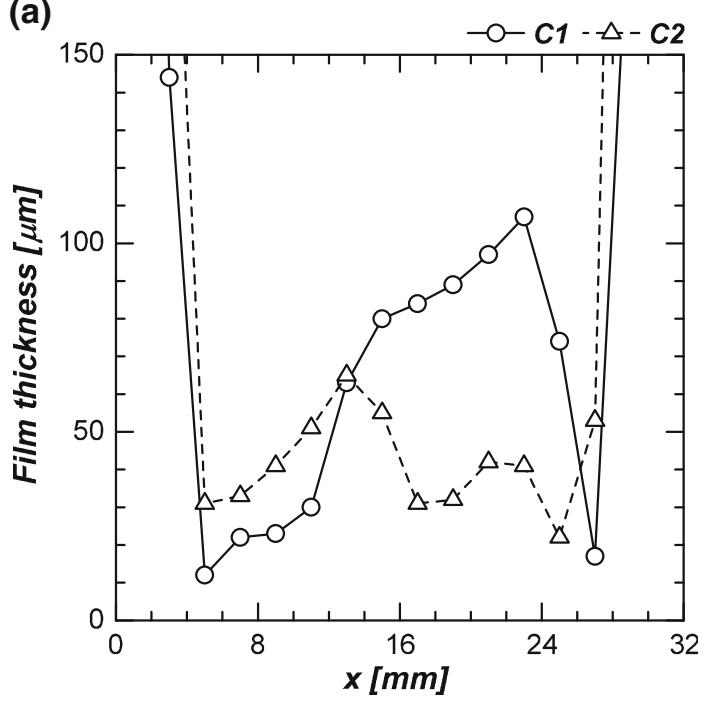

(b)

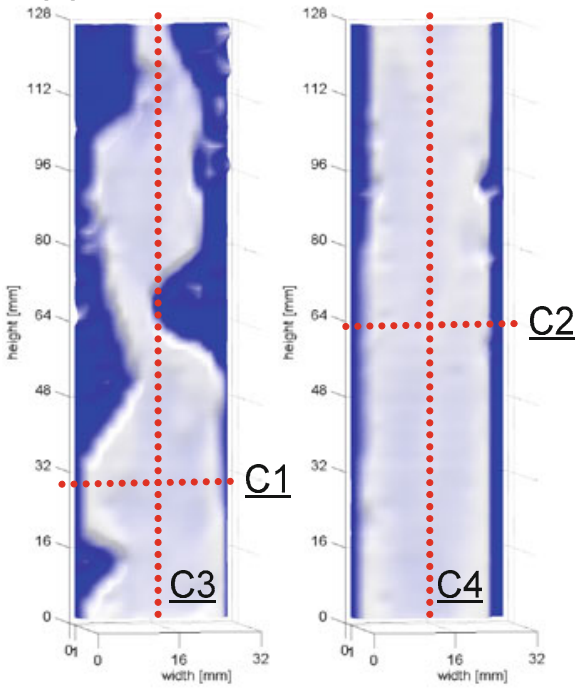

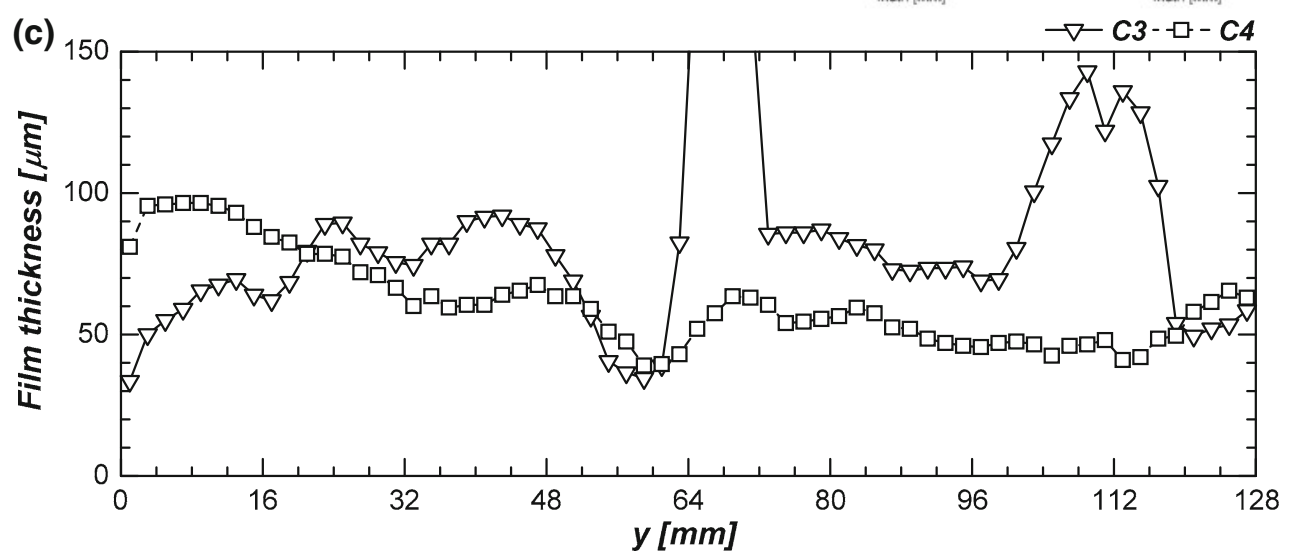

Fig. 20 Typical liquid film behavior in churn flow with $J_{L}=0.174 \mathrm{~m} / \mathrm{s}$; a magnified profile of film thickness along the channel width, b reconstructed bubble width distribution, c film thickness profile along the center line 
smaller in the middle of the bubble than at both sides. In flow direction, however, the bubble has no visible variation in film thickness, as shown for the film thickness along the center line B5 in Fig. 18c.

In Fig. 19, the slug bubbles also show the same tendency. In addition, the film thickness at the center of the slug bubbles is larger than for small bubbles, while the thickness at both sides is similar to those ones of smaller bubbles. The film thickness in the axial cuts shows more variation that for small bubbles. There is a tendency of an increase toward the head and the tail of the bubble.

Finally, the film thickness increases remarkably in the churn flow in Fig. 20. The films in churn flow have large variation regardless of the location on the gas bubbles. These results support and illustrate the observed tendencies in the average film thickness discussed in Sect. 4.4. Furthermore, there is a significant relationship between the film thickness and the bubble size.

\section{Conclusions}

An upward gas-liquid flow in a narrow gap was studied by the help of liquid film sensors developed by Damsohn and Prasser $(2009 a, b)$. The liquid film thickness distributions between bubbles and the wall were determined on a twodimensional domain and with high time resolution for the first time. The arrangement of sensors on both front and back walls of the test channel allowed measuring film thickness and void fraction simultaneously. The flow regime was varied from bubbly to churn flow. Furthermore, the bubble width distribution was reconstructed from the sensor signals, and the instantaneous and time averaged quantities were evaluated from the measured data. Finally, the liquid film on the individual bubble surface was estimated.

In the future, we plan to apply this technique to the rod bundle geometries and to extend the portfolio of signal evaluation methods. The measuring methods presented here offer the possibility to obtain detailed data for the clarification of the multidimensional flow structure in a narrow channel and for the validation of the CFD codes.

\section{References}

Damsohn M, Prasser HM (2009a) High-speed liquid film sensor for two-phase flows with high spatial resolution based on electrical conductance. Flow Meas Instrum 20:1-14

Damsohn M, Prasser HM (2009b) High-speed liquid film sensor with high spatial resolution. Meas Sci Technol. doi:10.1088/09570233/20/11/114001

Damsohn M, Prasser HM (2010) Experimental studies of the effect of functional spacers to annular flow in subchannels of a BWR fuel element. Nucl Eng Design 240(10):3126-3144. doi:10.1016/j. nucengdes.2010.05.032

Hibiki T, Mishima K (2001) Flow regime transition criteria for upward two-phase flow in vertical narrow rectangular channels. Nucl Eng Design 203:117-131

Ito D, Kikura H, Aritomi M (2010) Application of wire-mesh tomography to two-phase flow measurement in narrow channel. Trans Jpn Soc Mech Eng B 76-763:481-482. In Japanese

Iwamura T, Uchikawa S, Oku T, Kugo T, Akie H, Nakano Y, Nakatsuka $T$ (2006) Concept of innovative water reactor for flexible fuel cycle (FLWR). Nucl Eng Design 236:1599-1605

Kureta M (2007) Experimental study of three-dimensional void fraction distribution in heated tight-lattice rod bundles using three-dimensional neutron tomography. J Power Energy Syst 1(3):225-238

Ohnuki A, Kureta M, Yoshida H, Tamai H, Liu W, Misawa T, Takase $\mathrm{K}$, Akimoto H (2008) Development of design technology on thermal-hydraulic performance in tight-lattice rod bundles: I-master plan and executive summary. J Power Energy Syst 2(1):229-239

Prasser HM, Böttger A, Zschau J (1998) A new electrode-mesh tomograph for gas-liquid flows. Flow Meas Instrum 9(2):111-119

Sadatomi M, Kawahara A, Kano K, Tanoue S (2004) Flow characteristics in hydraulically equilibrium two-phase flows in a vertical 2.3 rod bundle channel. Int J Multiph Flow 30: 1093-1119

Tamai H, Kureta M, Ohnuki A, Sato T, Akimoto H (2006) Pressure drop experiments using tight-lattice 37-rod bundles. J Nucl Sci Technol 43(6):699-706

Yun BJ, Park GC, Julia JE, Hibiki T (2008) Flow structure of subcooled boiling water flow in a subchannel of $3 \times 3$ rod bundles. J Nucl Sci Technol 45(5):402-422 